\title{
Atomization Performance of an Atomizer with Internal Impingement*
}

\author{
Muh-Rong WANG ${ }^{* *}$, Tien-Chu LIN**, Teng-San LAI** and Ing-Ren TSENG ${ }^{* *}$
}

This paper describes the atomization performance of a newly designed atomizer with internal impinging mechanisms inside the atomizer. The spray drop size distribution was measured by a Malvern RT-Sizer. Results show that the Sauter mean diameter below $10 \mu \mathrm{m}$ has been achieved with GLR of 0.14 . The minimum mean drop size can be lowered to $4.0 \mu \mathrm{m}$ under a test condition of the liquid pressure and gas pressure of 2.5 bar and 3.5 bar, respectively. This test suggests that extra fine atomization on the liquid phase can be achieved under low pressure conditions using this particular atomizer. Such performance cannot be easily achieved with the conventional nozzle design. Results also show that better atomization performance can be achieved by increasing the internal impinging angle and the orifice diameter. An empirical formula of SMD, in terms of operating conditions and nozzle length scale is also presented in this paper.

Key Words: Atomization, Internal-Impingement, Impinging Angle, Twin-Fluid Atomizer

\section{Introduction}

Atomization involves the process disintegration of liquid matter into droplets to increase the specific surface area for engineering applications. Atomization of liquids is widely used in energy production system such as spray combustion in furnaces, gas turbines, diesel engines, and rockets. It is also employed in process industries such as spray drying, evaporative cooling, powder metallurgy, and spray painting as well as in medical applications such as the delivery of drugs to the lungs ${ }^{(1)}$. The atomization of most liquids can be achieved simply by creating a sufficiently high relative velocity between the liquid to be atomized and the surrounding gas. This is termed "twinfluid" or "air-assisted" atomization.

Researchers have studied twin-fluid atomization for more than three decades. For example, using different liquids, Lefebvre ${ }^{(2)}$ investigated the effects of liquid properties on the quality of atomization. The mechanisms of liquid sheet disintegration were further investigated by Chigier et al. and Samuelsen et al. Chigier first proposed two kinds of breakup modes: the mechanical mode and aerodynamic mode which are due to the action of liquid pressure inside the nozzle and the action of air friction, re-

\footnotetext{
* Received 25th May, 2004 (No. 04-5078)

** Institute of Aeronautics \& Astonautics, National Cheng Kung University, Tainan, Taiwan 70101, ROC.

E-mail: Wangmr@mail.ncku.edu.tw
}

spectively $^{(3)}$. Samuelsen proposed two different breakup mechanisms of the liquid sheet: the cellular breakup occurred at high relative velocity between air and liquid, and the stretched streamwise ligament breakup mechanism occurred at low liquid velocity ${ }^{(4)}$. A further example of twinfluid atomization includes the effervescent atomization, which is capable of producing fine water droplets ${ }^{(5),(6)}$. However, the device construction is more complex than other twin-fluid atomizers.

Air-assisted atomizers can be divided into two types: internal and external mixings, depending on where the first contact between the liquid and gas phase takes place. Performance of the internal-mixing atomizers with coaxial liquid feeding has been investigated, and the effects of nozzle design, load, and liquid and gas properties on spray characteristics been reported ${ }^{(7)-(9)}$. Semi-empirical equations are used to relate the mean droplet diameter as a function of those atomization parameters. However, their results are only applicable for the particular atomizer within the test conditions. Extending their results to the general applications becomes difficult since those equations were not derived from the first principal of physical laws to describe the complicated processes involved in atomization $^{(10)}$.

However, atomization with the internal mixing mechanisms normally elicits a finer spray. For example, ultrafine droplets (i.e., $D_{0.5} \leqq 10 \mu \mathrm{m}$ ) are produced by internal mixing atomizers at GLR as low as $1.0^{(7)}$. Therefore, if 
abrasion and fouling are not serious, internal-mixing atomizers are preferred due to their high efficiency of energy transfer from atomization gas to liquid.

Metal powder production using gas atomization techniques has become popular in recent years. The most adopted atomizer, called HPGA nozzles, belongs to external mixing type $\mathrm{e}^{(11)-(13)}$. Atomization on melt, using internal mixing atomizers, was extensively investigated by Wang et al. ${ }^{(14),(15)}$. Results show that the performance of this atomizer proved more successful than the conventional one with an external atomization. The ultrafine powder $(\mathrm{SMD}<13 \mu \mathrm{m})$ has been achieved at GLR $=$ $0.17^{(14)}$. Recently, Wang et al. ${ }^{(16)}$ carried out the atomization of melt using the atomizer with internal impinging mechanism. Result shows that the accumulative volume of the metal powder within $0-15 \mu \mathrm{m}$ is $56.9 \%$, i.e., more than half of the powder is within extra-fine range. It indicates that this particular design is a new atomization mechanism deserved to develop.

Although the atomization performance of the external and internal atomizer has been extensively studied in past decades, the internal structure of the atomizer has been somewhat neglected in the literature. In an effort to investigate the effects of internal impingement, this paper describes the atomization performance of a newly designed atomizer having internal impinging mechanisms inside the atomizer. The liquid stream is first injected to the distributor inside the mixing chamber. It results in two spray flows and these flows are introduced to the mixing zone of the atomizer. The secondary atomization processes takes place when the above two spray flows combine in the mixing zone. The two phase flow is then discharged through the orifice for further atomization. The effects of the internal impinging angle, and the operation conditions on the atomization performance, will be investigated.

\section{Nomenclature}

$$
\begin{gathered}
D_{0.5}: \text { volume median diameter }(\mu \mathrm{m}) \\
d_{0}: \text { diameter of nozzle orifice }(\mathrm{mm}) \\
l_{0}: \text { length of the nozzle orifice }(\mathrm{mm}) \\
\text { GLR }: \text { gas-to-liquid mass ratio } \\
\dot{M}_{\mathrm{G}}: \text { gas mass flow rate }(\mathrm{kg} / \mathrm{min}) \\
\dot{M}_{\mathrm{L}}: \text { liquid mass flow rate }(\mathrm{kg} / \mathrm{min}) \\
P_{\mathrm{G}}: \text { atomization pressure }(\mathrm{bar}) \\
P_{\mathrm{L}}: \text { liquid injection pressure }(\mathrm{bar}) \\
\mathrm{SMD}: \text { Sauter mean diameter }(\mu \mathrm{m}) \\
\alpha: \text { internal impinging angle }(\text { degree })
\end{gathered}
$$

\begin{tabular}{|c|c|c|}
\hline \multirow{2}{*}{ Inlet diameter } & Liquid $\left(d_{L}\right)$ & $\varnothing 1.3 \mathrm{~mm}$ \\
\hline & $\operatorname{Gas}\left(d_{G}\right)$ & Ø $1 / 4 " \times 2$ \\
\hline \multicolumn{2}{|c|}{ Outlet orifice diameter $\left(d_{0}\right)$} & Ø $2 \mathrm{~mm}, 3 \mathrm{~mm}, 4 \mathrm{~mm}$ \\
\hline \multicolumn{2}{|c|}{ Internal impinging angle $(\alpha)$} & $67.5^{\circ}, 57.5^{\circ}, 47.5^{\circ}$ \\
\hline \multirow{2}{*}{ Pressure } & Liquid $\left(\mathbf{P}_{\mathbf{L}}\right)$ & $1.5 \sim 5.0 \mathrm{bar}$ \\
\hline & $\operatorname{Gas}\left(\mathbf{P}_{\mathrm{G}}\right)$ & $1.0 \sim 6.0$ bar \\
\hline
\end{tabular}

\section{Experimental Setup}

Figure 1 shows the schematic of the atomizer used in this paper. The pressurized air is supplied through two 1/4-inch tubes from two sides of the atomizer. The pressurized liquid is fed through a $1.3 \mathrm{~mm}$ hole from the top. The design parameters of the atomizer are including inter-

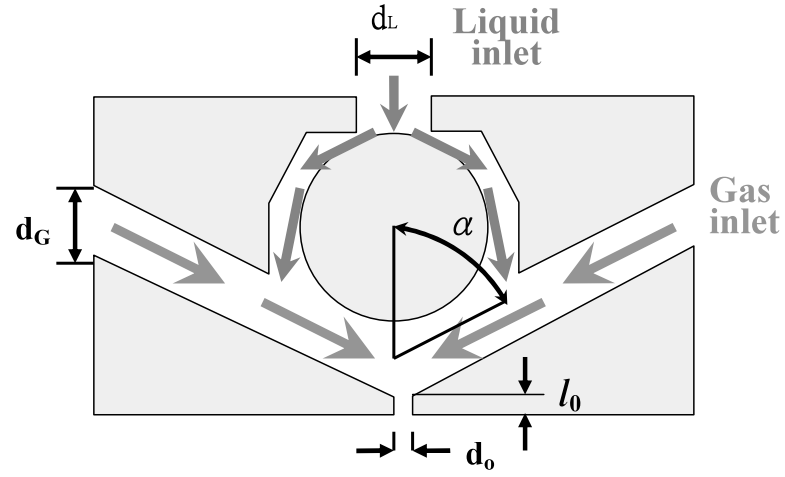

Fig. 1 Schematic of the internal impinging atomizer

Table 1 Test matrix

nal impinging angle and the orifice diameter. The orifice diameter covers a range of length scale, i.e., $d_{0}=2-4 \mathrm{~mm}$ with the length of the orifice, $l_{0}$, equal to $0.5 \mathrm{~mm}$. The internal impinging angle varies from $47.5^{\circ}$ to $67.5^{\circ}$.

The experimental setup is shown in Fig. 2. The test stand is designed for a down-sprayed type atomization experiment. It consists of a spray chamber, an optical table, a collection tank, and an exhaust fan. Liquid was delivered from a pressurized water tank and gas supplied from a compressed air tank. The pressures of the liquid and gas phase were measured by a Huba Control digital pressure gauge with an accuracy of $\pm 0.3 \%$. The mass flow rates of liquid and gas phase were measured by HOSCO HONSBERG flowmeter and AALBORG mass flowmeter, allowing for maximum errors of $\pm 2 \%$ and $\pm 1.5 \%$, respectively. The test matrix is shown in Table 1.

The spray drop size distribution is measured by a Malvern RT-Sizer, which uses the Fraunhofer diffraction technique. As seen in Fig. 3, the laser beam is expanded to $5 \mathrm{~mm}$ diameter in the transmitter and becomes diffracted when passing through the spray. The diffracted light is received by the photo detector through the Fourier lens and transferred to digital signal by the A/D converter. And finally, the software of the processor calculates the droplet size distribution.

The spray size is measured at $100 \mathrm{~mm}$ downstream of the discharge orifice. The spray drop size was characterized as Sauter mean diameter, SMD, having a maximum error of $\pm 5 \%$. Test data were obtained by averaging results of five test runs and the error bars were illustrated in the figures. 


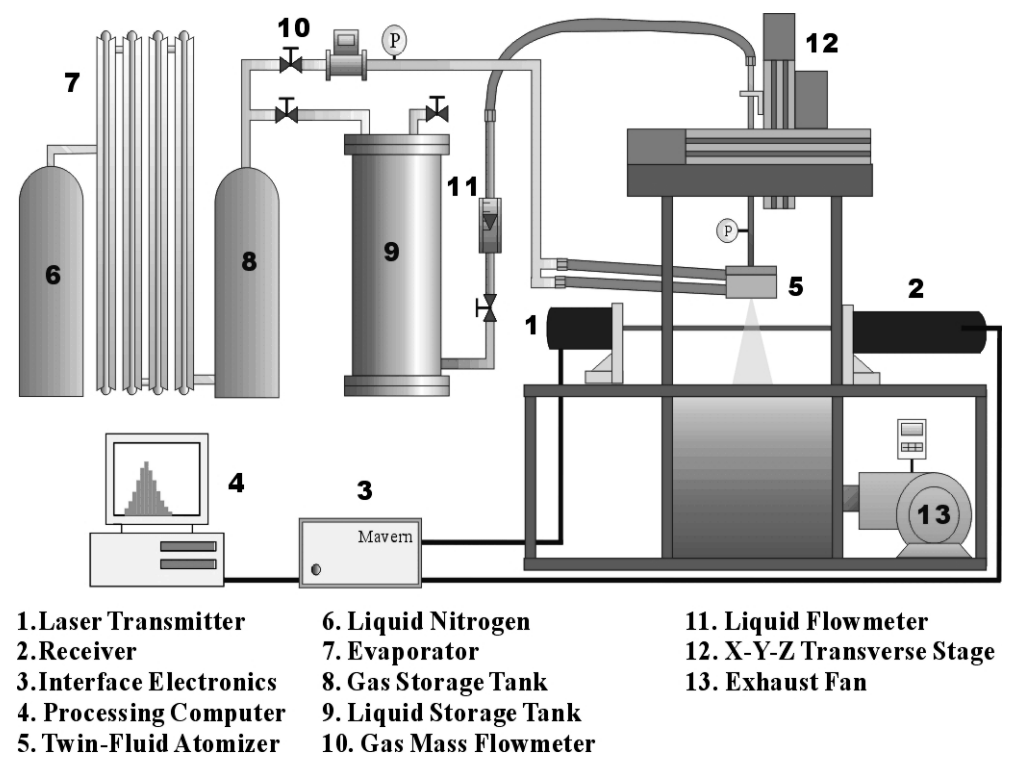

Fig. 2 Schematic of the experimental setup

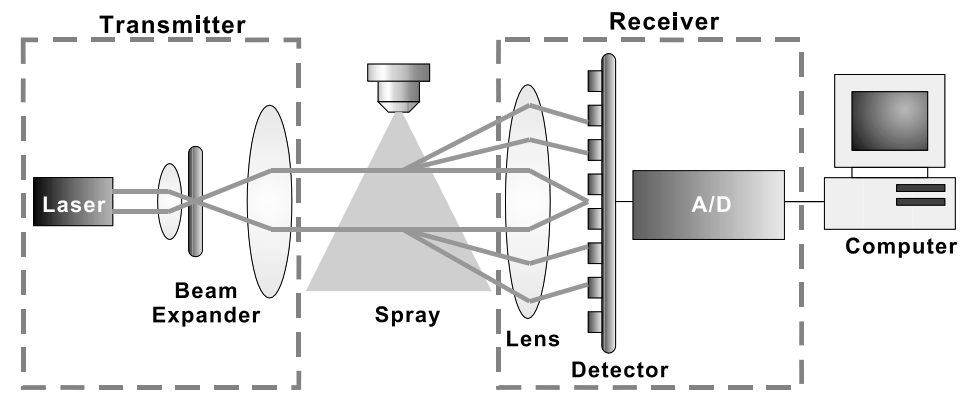

Fig. 3 The working principle of Malvern RT-Sizer

\section{Results and Analysis}

\subsection{Atomization characteristics}

The influence of atomization pressure on the liquid flow rate and gas flow rate, with given liquid pressure, is shown in Figs. 4 and 5. As Fig. 4 reveals, by keeping the liquid pressure at $1.5 \mathrm{bar}$, the liquid flow rate decreases from $0.49 \mathrm{~kg} / \mathrm{min}$ to $0.18 \mathrm{~kg} / \mathrm{min}$ as the atomization pressure increases from 1.0 bar to 2.0 bar. While raising the liquid pressure to 5.0 bar, the liquid flow rate decreases from $0.97 \mathrm{~kg} / \mathrm{min}$ to $0.26 \mathrm{~kg} / \mathrm{min}$ as gas pressure increases from 1.0 bar to 6.0 bar. It seems that the working range of flow rate and atomization pressure increases at a higher liquid pressure. This trend also appears in the change of the turn-down ratio, $\left(\dot{M}_{\mathrm{L}}\right)_{\max } /\left(\dot{M}_{\mathrm{L}}\right)_{\min }$, which increases from 2.7 to 3.7 as liquid pressure increases from 1.5 bar to 5.0 bar.

This phenomenon can be explained by the effect of the pressure balance of liquid stream and atomization gas in the mixing chamber. Since the volume of the liquid phase is negligible in the mixing chamber, the pressure of the atomization gas stream dominates the balance pressure in the mixing chamber. The liquid flow rate depends on

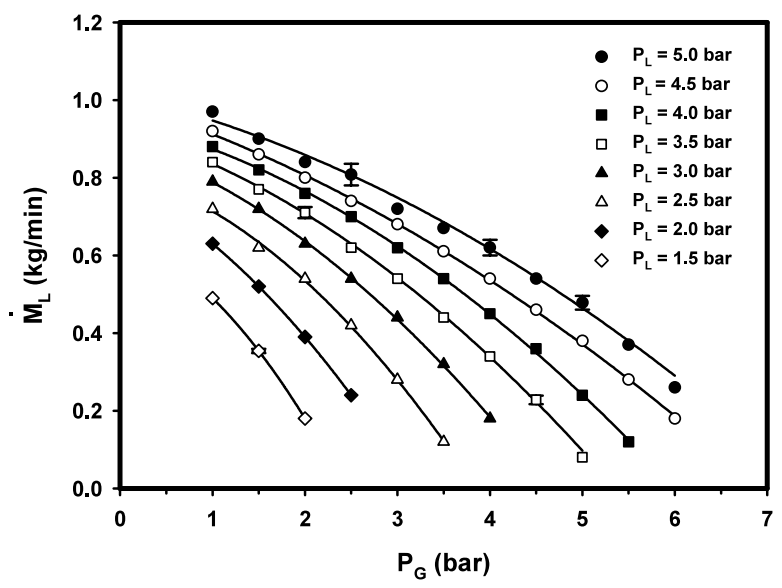

Fig. 4 Dependence of liquid flow rate on atomization pressure

a driving force that is proportional to the pressure difference between the liquid injection pressure and the balance pressure in the mixing chamber. Since such pressure difference reduces as the atomization gas pressure increases, the liquid flow rate decreases as well. It turns out that the liquid pressure essentially controls the working range of the liquid flow rates and the atomization gas pressure. Furthermore, the liquid flow rate decreases as the atomiza- 


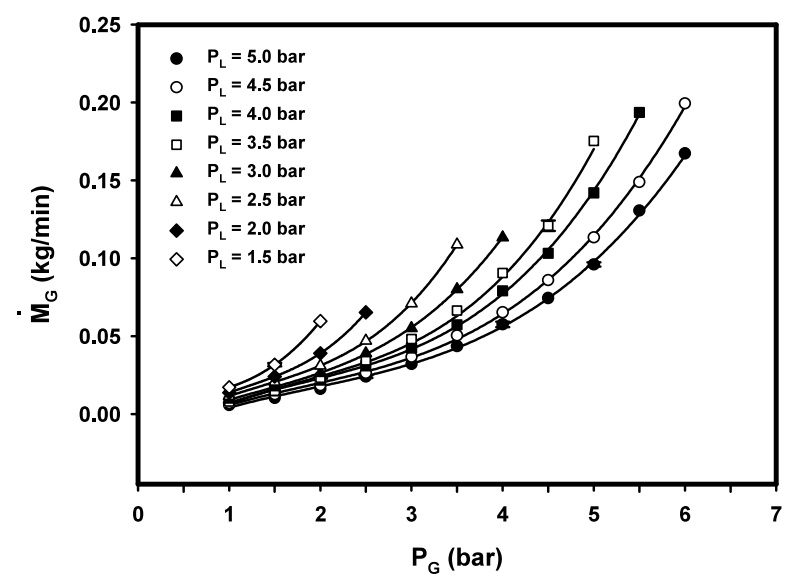

Fig. 5 Dependence of gas flow rate on atomization pressure

tion pressure increases because of the decreasing pressure difference. Ultimately, the liquid flow is eventually terminated when the liquid pressure is less than the balance pressure in the mixing chamber. This occurrence also determines the operation range of the atomizer.

Figure 5 shows that the gas flow rate increases from $0.02 \mathrm{~kg} / \mathrm{min}$ to $0.12 \mathrm{~kg} / \mathrm{min}$ as the atomization pressure increases from 1 bar to 2 bar, while the liquid pressure remains at 1.5 bar. Significant increase in gas flow rate occurs when the atomization pressure further increases. For example, while the liquid pressure remains at $5.0 \mathrm{bar}$, the gas flow rate increases from $0.01 \mathrm{~kg} / \mathrm{min}$ to $0.17 \mathrm{~kg} / \mathrm{min}$ as the atomization pressure increases from 1.0 bar to 6.0 bar. Since the gas flow rate is proportional to the pressure difference between the atomization gas and the mixing chamber, the gas flow rate increases as the atomization pressure increases. Furthermore, the ratios of working pressure of the atomization gas, $\left(P_{\mathrm{G}}\right)_{\max } /\left(P_{\mathrm{G}}\right)_{\min }$, increase from 2.0 to 6.0 as the liquid pressure increases from 1.5 bar to 5.0 bar. These increases, in turn, result in a wide range of the mean drop size for different engineering applications to be discussed below.

Figure 6 shows the dependence of Sauter mean diameter on atomization pressure. The SMD of the droplets decreases from $35.95 \mu \mathrm{m}$ to $8.49 \mu \mathrm{m}$ as the atomization pressure increases from 1.0 bar to 2.0 bar, while the liquid pressure remains at 1.5 bar. The variation of droplet size increases as the liquid pressure increases. For example, the SMD of droplet decreases from $57.48 \mu \mathrm{m}$ to $4.42 \mu \mathrm{m}$ as atomization pressure increases from 2.0 bar to 6.0 bar, the liquid pressure, however, remains at 5.0 bar. As a result, the mean drop size reduces as a factor of 13th when atomization pressure increases 3 times as much. It indicates that the effects of atomization have been enhanced at the higher atomization pressure.

The improvement of the atomization process results from the decreases of liquid mass flow rate and the increases of gas mass flow rate as atomization pressure in-

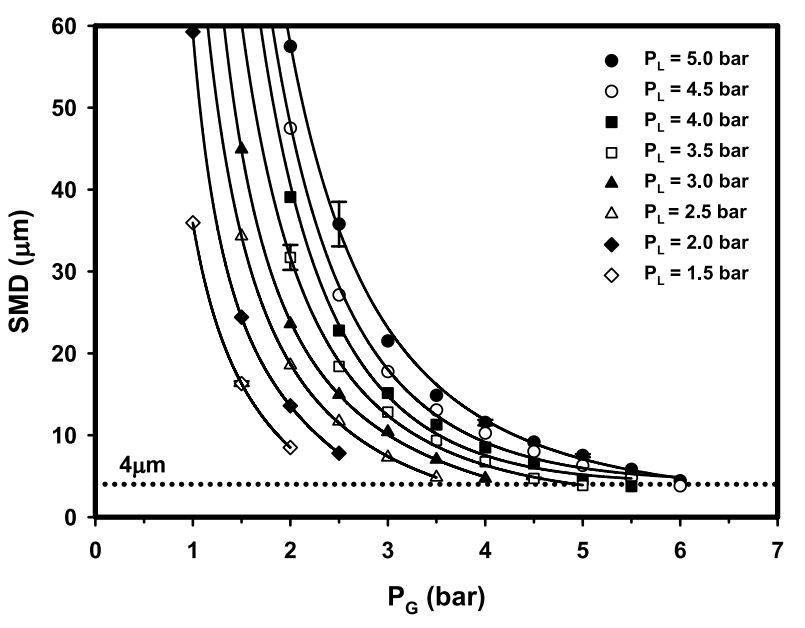

Fig. 6 Dependence of SMD on atomization pressure

creases, as reflected in Figs. 4 and 5. The enhancement of the atomization process, then, may be due to the increase of atomization energy at high pressure. It turns out that greater atomization performance can be achieved by raising atomization pressure. Further increase in atomization pressure, however, will cause an unstable flow of liquid stream. The liquid flow will terminate when the gas pressure is further increased. No atomization can be observed under such condition.

In an effort to indicate the operation limit of the atomizer, a dash line drawn at $\mathrm{SMD}=4.0 \mu \mathrm{m}$ is further shown in Fig. 6. The minimum mean drop size can be lowered to $4.0 \mu \mathrm{m}$, under a test condition of liquid pressure and gas pressure of 2.5 bar and 3.5 bar, respectively. This test suggests that extra fine atomization on the liquid phase can be achieved under low pressure conditions using this particular atomizer. It can be regarded as the special feature of the atomization process associated with this atomizer. Such performance cannot be easily achieved with the conventional nozzle design.

The above results can be further explained by the dependence of Sauter mean diameter on gas-to-liquid mass ratio (see Fig. 7). As indicated, the SMD of the droplets decreases monotonically from $60.0 \mu \mathrm{m}$ to $6.0 \mu \mathrm{m}$ as the GLR increases from 0.02 to 0.3 . The mean drop size below $10 \mu \mathrm{m}$ has been achieved with the GLR as low as 0.14 . Figure 7 also compares the atomization performance of the present atomizer to the data of the effervescent atomizer reported by Whitlow and Lefebvre ${ }^{(6)}$, and the internalmixing atomizer reported by Guo et al. ${ }^{(9)}$. The atomization pressures described in the present paper, Whitlow ${ }^{(6)}$, and $\mathrm{Guo}^{(9)}$, are 1.0 bar to 6.0 bar, 6.89 bar, and 3.0 bar to 8.0 bar, respectively. Figure 7 , then, suggests that the atomization performance compares favorably to the other two atomizers in terms of the mass of atomization gas required for the atomization of unit mass of liquid. For example, the GLR is as low as 0.06 with the internal im- 
pinging atomizer compared to GLR $=0.09$ and 0.16 , respectively, while the other two atomizers obtain the spray with $\mathrm{SMD}=16 \mu \mathrm{m}$. The figure further reveals that less than half of the atomization gas is required to obtain the same amount of fine spray with a mean drop size less than $16 \mu \mathrm{m}$. However, the effervescent atomizer ${ }^{(6)}$ achieves a better performance in producing the spray with mean drop size over $25 \mu \mathrm{m}$.

\subsection{Effects of design parameters}

Dependence of the atomization performance on the design parameters of the atomizer is also investigated in this paper. The design parameters include the internal impinging angle and the orifice diameter. Figure 8 illustrates the dependence of expansion angle of the spray on atomization pressure and internal impinging angle of the atomizer. The expansion angle is defined as the cone angle of the spray near the outlet of the orifice. The photograph and the schematic of the expansion angle are shown in Fig. 9. It demonstrates the near field phenomenon of the spray. Figure 8 conveys that the spray expansion angle increases from $42^{\circ}$ to $91^{\circ}$ as the atomization pressure increases from 2.0 bar to $5.0 \mathrm{bar}$, with an internal imping-

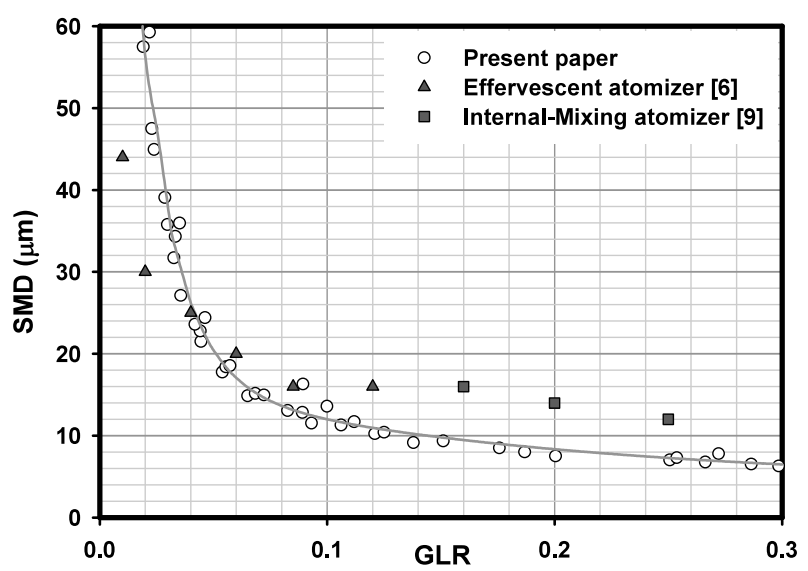

Fig. 7 Dependence of SMD on GLR ing angle of $67.5^{\circ}$. However, the spray expansion angle decreases from $91^{\circ}$ to $79^{\circ}$ as atomization pressure further increases to 6.0 bar. This phenomenon can be explained by the balance of increased momentum of atomization gas and decreased momentum of the liquid flow as the atomization pressure increases. Increased atomization pressure will cause increased momentum of atomization gas. This increase, in turns, results in the increase of the spray expansion angle. However, as mentioned above, the liquid flow rate decreases significantly when the atomization pressure is higher than 5.0 bar. The mass of the liquid phase concentrates in the center of the orifice due to the internal impingement of gas flow under this condition. Hence the spray expansion angle decreases as well.

Figure 8 also illustrates the dependence of expansion angles of the spray on the impinging angles of atomizers. As seen in Fig. 8, the expansion angle increases from $36^{\circ}$ to $50^{\circ}$ as the impinging angle increases from $47.5^{\circ}$ to $67.5^{\circ}$, while the atomization pressure remains at 3.0 bar. As the impinging angle increases, the horizontal compo-

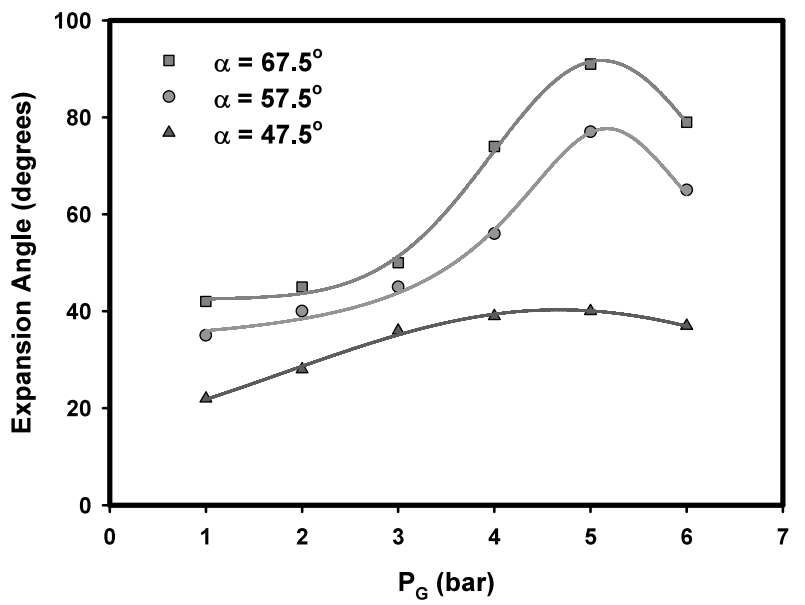

Fig. 8 Dependence of spray expansion angle on atomization pressure

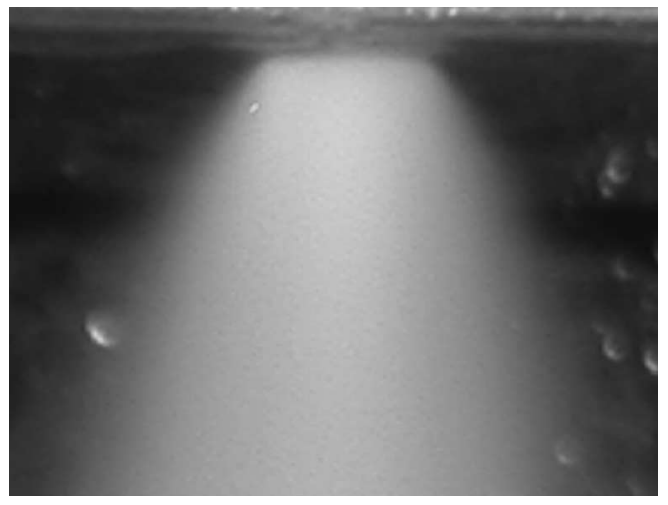

(a)

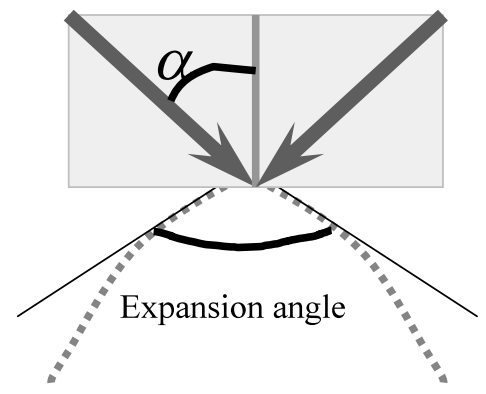

(b)

Fig. 9 The flow pattern near the nozzle exit (a) photograph of the spray (b) schematic of expansion angle 


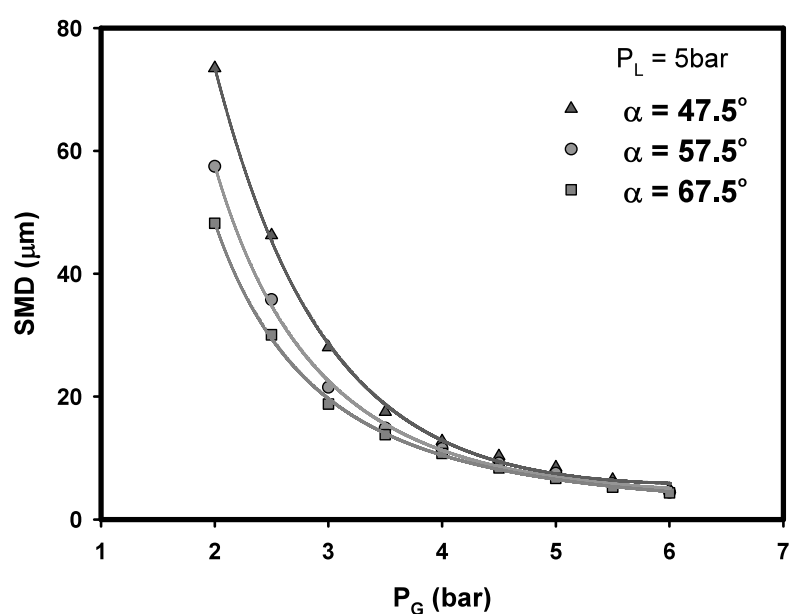

Fig. 10 Dependence of SMD on internal impinging angle

nent of gas velocity increases, and the expansion angle increases as well. Moreover, the spray film becomes thinner as the expansion angle increases, and results in a better atomization of the liquid phase. This result can also be confirmed from Fig. 10, which illustrates the dependence of SMD on internal impinging angles. In this figure, SMD decreases from $28.04 \mu \mathrm{m}$ to $18.80 \mu \mathrm{m}$ as the impinging angle increases from $47.5^{\circ}$ to $67.5^{\circ}$, under the atomization pressure of 3.0 bar. It implies that better atomization performance can be achieved by increasing the internal impinging angle.

Figure 11 further illustrates the dependence of SMD on orifice diameter of the atomizer. As shown in the figure, the SMD decreases from $57.48 \mu \mathrm{m}$ to $13.45 \mu \mathrm{m}$ as the orifice diameter increases from $2 \mathrm{~mm}$ to $4 \mathrm{~mm}$ by keeping the gas pressure at 2 bar. This is due to the increase of the gas-to-liquid mass ratio as the orifice diameter increases. It reveals that the better atomization performance can also be achieved by controlling the orifice size of the atomizer.

\subsection{Correlation}

An empirical formula includes the operating conditions and the design parameters of the atomizer is shown as Eq. (1).

$$
\begin{aligned}
\mathrm{SMD}= & \left(4.4-0.4 d_{0}\right)(\tan \alpha)^{-0.4} \\
& \times\left(\frac{P_{\mathrm{G}}+0.3}{P_{\mathrm{L}}+2.3}\right)^{\left(-6.3+2.6 d_{0}-0.4 d_{0}^{2}\right)}
\end{aligned}
$$

The correlation formula related SMD to the operating conditions, $P_{\mathrm{G}}$ and $P_{\mathrm{L}}$, and the design parameters, $d_{0}$ and $\alpha$. In Eq. (1), $d_{0}$ is the orifice diameter and $\alpha$ is the internal impinging angle of the atomizer. This formula can be applied to different atomizers shown in this paper covering entire range of pressure. More than 300 measured data points and five atomizers with different design are tested on this formula, yielding an average error of $7.0 \%$. A coefficient of correlation of the calculated and measured SMD is as 0.993, which is shown in Fig. 3. It is believed that this equation has been well fitted to the performance of these

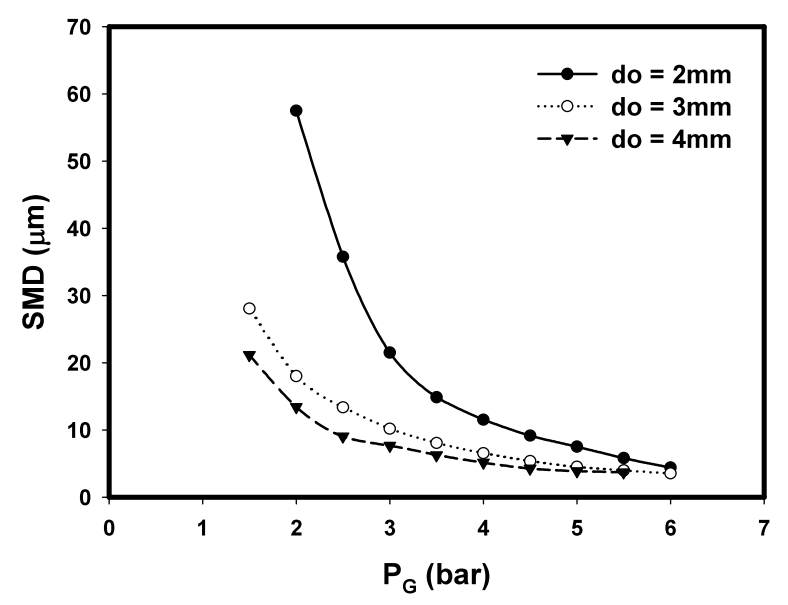

Fig. 11 Dependence of SMD on the diameter of nozzle orifice

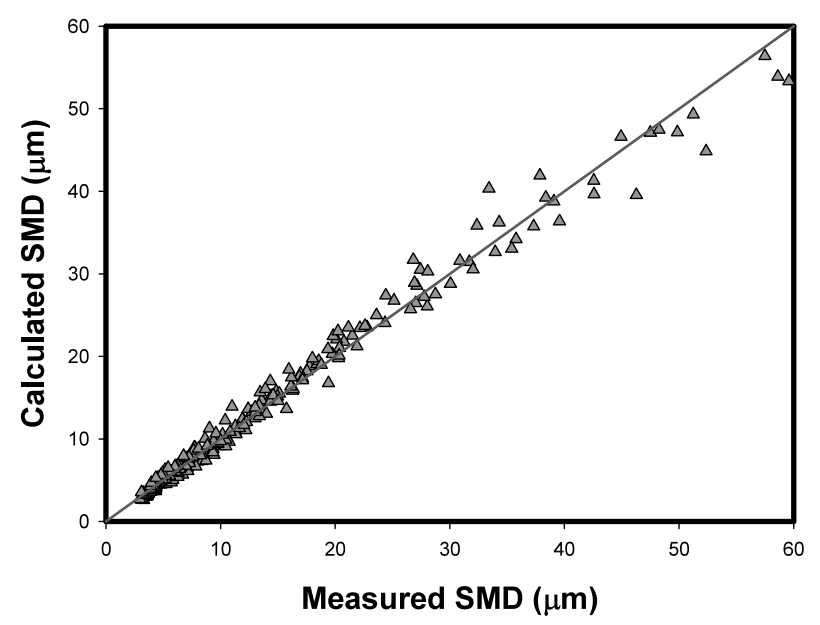

Fig. 12 Plot of calculated and measured SMD

atomizers.

\section{Conclusions}

The atomization performance of a newly designed atomizer having internal impinging mechanisms has been described. Results show that the Sauter mean diameter below $10 \mu \mathrm{m}$ has been achieved with a GLR as low as 0.14 . The minimum mean drop size can be further lowered to $4.0 \mu \mathrm{m}$ under a test condition of liquid pressure and gas pressure of 2.5 bar and 3.5 bar, respectively. This test suggests that extra fine atomization on the liquid phase can be achieved under low pressure conditions using this particular atomizer. Such performance cannot be easily achieved with the conventional nozzle design. As compared to the atomization performance of effervescent atomizer and the internal-mixing atomizer, the atomization efficiency of the atomizer with internal impinging mechanisms is higher than the other two atomizers having a mean drop size below $25 \mu \mathrm{m}$. Results also show that SMD reduces from $28.04 \mu \mathrm{m}$ to $18.80 \mu \mathrm{m}$ as the impinging angle increases from $47.5^{\circ}$ to $67.5^{\circ}$, under the atomization pressure of 3.0 bar. The SMD reduce from $57.48 \mu \mathrm{m}$ to 
$13.45 \mu \mathrm{m}$ as the orifice diameter increase from $2 \mathrm{~mm}$ to $4 \mathrm{~mm}$ under the atomization pressure of 2.0 bar. This implies that better atomization performance can be achieved by increasing the internal impinging angle and orifice size. An empirical formula includes operating conditions and the design parameters of the atomizer are also presented in this paper.

\section{Acknowledgements}

This research was supported by National Science Council and Ministry of Economy of Republic of China under contract No. NSC91-2622-E-006-087 and TDPA91EC-17-A-05-SI-0014. The support from Center for Micro-Nano Technology, National Cheng Kung University and the contribution of Dr. Ming-Shen Sheu are also addressed.

\section{References}

( 1 ) Lefebvre, A.H., Atomization and Sprays, (1989), ISBN 0-89116-603-3, ISSN 1040-2765, Hemisphere Publishing Corporation.

( 2 ) Beck, J.E. and Lefebvre A.H., Airblast Atomization at Conditions of Low Air Velocity, J. Propulsion, Vol.7, No.2 (1991), pp.155-170.

( 3 ) Mansour, A. and Chigier, N., Disintegration of Liquid Sheets, Phys. Fluids, Vol.A2 (1990), pp.706-719.

(4) Stapper, B.E. and Samuelsen, G.S., An Experimental Study of the Effects of Liquid Properties on the Breakup of a Two Dimensional Liquid Sheet, J. Eng. For Gas Turbine and Power, Vol.114 (1992), pp.39-45.

( 5 ) Sovani, S.D., Sojka, P.E. and Lefebvre, A.H., Effervescent Atomization, Progress in Energy and Combustion Science, Vol.27 (2001), pp.483-521.

( 6 ) Whitlow, J.D. and Lefebvre, A.H., Effervescent Atomizer Operation and Spray Characteristics, Atomization Sprays, Vol.3 (1993), pp.137-156.

( 7 ) Nguyen, D.A. and Rhodes, M.J., Producing Fine Drops of Water by Twin-Fluid Atomization, Powder Technol- ogy, Vol.99 (1998), pp.285-292.

( 8 ) Kufferath, A., Wende, B. and Leuckel, W., Influence of Liquid Flow Conditions on Spray Characteristics of Internal-Mixing Twin-Fluid Atomizers, Int. J. Heat and Fluid Flow, Vol.20 (1999), pp.513-519.

(9) Guo, L.J., Li, G.J., Chen, B., Chen, X.J., Papailiou, D.D. and Panidis, Th., Study on Gas-Liquid Two-Phase Spraying Characteristics of Nozzles for the Humidification of Smoke, Experimental Thermal and Fluid Science, Vol.26 (2002), pp.715-722.

(10) Chigier, N.A., The Physics of Atomization, Proc. ICLASS-1991, Gaithersburg, MD, USA., Pub NIST 813, pp.1-15.

(11) Anderson, I.E. and Terpstra, R.L. Progress Toward Gas Atomization Processing with Increased Uniformity and Control, Materials Science and Engineering, A, Vol.326 (2002), pp.101-109.

(12) Lavernia, E.J., Srivatsan, T.S. and Rangel, R.H., Atomization of Alloy Powders, Atomization and Sprays, Vol.2 (1992), pp.253-274.

(13) Ting, J., Peretti, M.W. and Eisen, W.B., The Effect of Wake-Closure Phenomenon on Gas Atomization Performance, Materials Science and Engineering, A, Vol.326 (2002), pp.110-121.

(14) Wang, M.R., Sheu, M.S. and Yang, S.R., Performance of a Linear Internal Mixing Atomizer in Atomization of Molten Metals, Proc. ILASS 2000, Pasadena, USA.

(15) Wang, M.R., Lin, T.C., Yang, C.J., Kuo, Z.Z. and Sheu, M.S., Low Pressure Atomization Process of Molten Metal in a Linear Internal Mixing Atomizer, Transaction of the Aeronautical and Astronautical Society of the Republic of China, Vol.36, No.3 (2005), pp.269274

(16) Wang, M.R., Lai, T.S., Lin, T.C., Chiu, C.H. and Yang, C.J., Optimization of Metal Powder Production by Gas Atomization Processes with Internal-Mixing Mechanism, Transactions of the Aeronautical and Astronautical Society of the Republic of China, Vol.37, No.2 (2005), pp.153-162. 